\title{
O jogo computacional como ferramenta de ensino e aprendizagem para alunos com dislexia - uma experiência nas salas multifuncionais de Cerro Largo - RS
}

\author{
Jeize de Fátima Batista , Ana Cecilia Teixeira \\ Gonçalves ${ }^{2}$, Cleusa Inês Ziesmann
}

Resumo: Este trabalho consiste em aplicar atividades de um software, desenvolvido pela coordenadora da proposta do projeto de extensão, em alunos da rede municipal da cidade de Cerro Largo diagnosticados com dislexia. As atividades propostas servem como estímulos para aumentar e potencializar a consciência fonêmica, a partir de jogos de identificação e reconhecimento de letras, palavras, frases, rimas e sons, analisando sua eficácia por meio da comparação dos desempenhos obtidos em testes de leitura realizados antes e após a utilização do aplicativo Estimugame. Dessa forma, o objetivo principal deste projeto é colaborar com os professores que atuam na sala de recursos, propiciando ferramentas próprias para estimular a leitura em alunos com dislexia. Nesse sentido, a partir do projeto de extensão, tem-se possibilitado que muitos alunos com dislexia recebam um auxílio específico para as dificuldades de leitura, o que vem se mostrando eficaz a cada semana. Todos os participantes estão acompanhando e superando, mesmo que lentamente, suas limitações, buscando melhorar a cada etapa do projeto. Assim, esperamos auxiliar os profissionais da educação diante das dificuldades que os alunos apresentam em relação à dislexia, respeitando as suas limitações e a subjetividade de cada criança para vencer seus obstáculos e construir os seus conhecimentos.

Palavras-chave: Distúrbio de leitura. Inclusão escolar. Instrumentalização a alunos e a professores.

Área Temática: Educação.

\section{The computational game as a teaching and learning tool for students with dyslexia - an experience in multifunctional rooms in Cerro Largo - $R S$}

\begin{abstract}
This work consists of applying software activities, developed by the coordinator of the extension project proposal, to students from the municipal network of the city of Cerro Largo diagnosed with dyslexia. The proposed activities serve as stimuli to increase and potentiate phonemic awareness, from games of identification and recognition of letters, words, phrases, rhymes and sounds, analyzing their effectiveness by comparing the performance obtained in reading tests performed before and after using the Estimugame application. Thus, the main objective of this project is to collaborate with teachers who work in the resource room, providing their own tools to stimulate reading in students with dyslexia. In this sense, from the extension project, it has been possible that many students with dyslexia receive specific assistance for reading difficulties,
\end{abstract}

\footnotetext{
${ }^{1}$ Doutora em Letras, professora de Língua Portuguesa e práticas de Ensino da Universidade Federal da Fronteira Sul - UFFS/ Campus de Cerro Largo. Coordenadora do Projeto de extensão, líder do grupo de pesquisa GEPETEC. E-mail: jeize.batista@uffs.edu.br

${ }^{2}$ Doutora em Letras, professora de Língua Portuguesa e práticas de Ensino da Universidade Federal da Fronteira Sul - UFFS/ Campus de Cerro Largo. Colaboradora do Projeto de extensão, participante do grupo de pesquisa GEPETEC. E-mail: acgteixeira@uffs.edu.br

${ }^{3}$ Doutora em Educação, professora de Libras da Universidade Federal da Fronteira Sul - UFFS/ Campus de Cerro Largo. Colaboradora do Projeto de extensão, participante do grupo de pesquisa GEPETEC .E-mail: cleusa.ziesmann@uffs.edu.br
} 
which has been proving effective every week. All participants are monitoring and overcoming, even if slowly, their limitations, seeking to improve at each stage of the project. Thus, we hope to help education professionals in the face of the difficulties that students have in relation to dyslexia, respecting their limitations and the subjectivity of each child to overcome their obstacles and build their knowledge.

Keywords: Reading disorder. School inclusion. Instrumentalization to students and teachers.

\section{El juego de computadora como herramientas de enseñanza-aprendizaje para estudiantes con dislexia - una experiencia en las aulas de Cerro Largo multifuncional - $R S$}

Resumen: Este trabajo consiste en la aplicación de actividades de software, desarrolladas por el coordinador de la propuesta de proyecto de extensión, a estudiantes de la red municipal de la ciudad de Cerro Largo con diagnóstico de dislexia. Las actividades propuestas sirven como estímulos para incrementar y potenciar la conciencia fonémica, a partir de juegos de identificación y reconocimiento de letras, palabras, frases, rimas y sonidos, analizando su efectividad comparando el desempeño obtenido en las pruebas de lectura realizadas antes y después de usar la aplicación Estimugame. Así, el principal objetivo de este proyecto es colaborar con los profesores que trabajan en la sala de recursos, aportando sus propias herramientas para estimular la lectura en alumnos con dislexia. En este sentido, desde el proyecto de ampliación, ha sido posible que muchos alumnos con dislexia reciban una asistencia específica para dificultades lectoras, que ha demostrado ser eficaz todas las semanas. Todos los participantes están monitoreando y superando, aunque sea poco a poco, sus limitaciones, buscando la mejora en cada etapa del proyecto. Así, esperamos ayudar a los profesionales de la educación ante las dificultades que tienen los estudiantes en relación a la dislexia, respetando sus limitaciones y la subjetividad de cada niño para superar sus obstáculos y construir sus conocimientos.

Palabras clave: Trastorno de lectura. Inclusión escolar. Instrumentalización a estudiantes y profesores.

\section{INTRODUÇÃO}

Atualmente vivemos na "era digital" e muitos recursos tecnológicos têm sido incluídos nas salas de aula como ferramentas no processo de ensino-aprendizagem dos alunos, nas mais diversas áreas do conhecimento. Também, avanços tecnológicos têm buscado meios para auxiliar alunos com dificuldades de aprendizagem, como a dislexia. Nesse caminho, conforme a Organização das Nações Unidas para a educação, à ciência e a cultura (UNESCO):

O uso da tecnologia na educação desempenha o papel vital de permitir o desenvolvimento de um currículo flexível e de ajudar os alunos com deficiências a participar de maneira mais igualitária da experiência de ensino. A tecnologia também ajuda a prepará-los para o aprendizado ao longo da vida, bem como para o entretenimento e para o trabalho fora do ambiente escolar (UNESCO, 2011, p. 5).

Assim, percebe-se que a tecnologia desempenha um papel fundamental na garantia de um ensino personalizado, possibilitando o desenvolvimento de um currículo flexível e ajudando os alunos com deficiências a participar, através das Tecnologias de Informação e Comunicação (TICs) acessíveis, de maneira igualitária na experiência de aprendizagem (UNESCO, 2011).

Nesse contexto, acredita-se que o uso das tecnologias com jogos educativos possa contribuir como metodologia de intervenção no processo de construção e desenvolvimento de habilidades e consciência fonológica. Este trabalho trata do jogo computacional como ferramenta no processo de ensino-aprendizagem de crianças 
com dislexia e se utiliza de um software ${ }^{4}$ para aplicação prática em alunos diagnosticados com dislexia das escolas municipais de Cerro Largo/RS. O Projeto de extensão foi aprovado no EDITAL No 1098/GR/UFFS/ 2017 com apoio para bolsista e ainda contou com a participação de duas professoras colaboradoras e mais alunos voluntários do Curso de Letras da UFFS- Cerro Largo.

Neste artigo, busca-se apresentar as ações de extensão desenvolvidas. Para tanto, está organizado da seguinte forma: primeiramente, apresentam-se os objetivos pretendidos e os procedimentos metodológicos utilizados; em seguida, discutem-se os resultados obtidos com a ação; em momento posterior, aborda-se sobre o uso dos jogos computacionais como ferramentas de ensino, momento em que se trata da Tecnologia da Informação e Comunicação (TICS) e da Tecnologia Assistiva (TA) como recursos tecnológicos que podem auxiliar o trabalho do professor; ainda nessa parte, discorre-se sobre os jogos computacionais como uma metodologia de intervenção e se expõe uma revisão sobre o uso dos jogos como intervenção às dificuldades de aprendizagem. Por fim, fazem-se as considerações gerais, apresentando os resultados parciais do desenvolvimento do projeto (que ainda está em andamento).

\section{OBJETIVO}

Motivada pelos resultados obtidos nas pesquisas feitas e apresentadas no decorrer deste trabalho, foi desenvolvido o software Estimugame como estratégia de intervenção para os problemas de leitura detectados em crianças e jovens diagnosticados com dislexia. Assim, depois de aprovado o software, elaborou-se um projeto de extensão a fim de aplicar e analisar sua eficácia por meio da comparação dos desempenhos obtidos em testes de leitura realizados antes e após a utilização do aplicativo em alunos das escolas municipais de Cerro Largo. Com isso, o presente artigo tem como objetivo principal em colaborar com os professores que atuam na sala de recursos com ferramentas próprias para estimular a leitura em alunos com dislexia.

\section{METODOLOGIA}

O projeto de extensão consiste em aplicar atividades do software Estimugame, desenvolvido pela coordenadora da proposta do projeto de extensão, em alunos da rede municipal de Cerro Largo, diagnosticados com dislexia. As atividades propostas servem como estímulos para aumentar a consciência fonêmica, a partir de jogos de identificação e reconhecimento de letras, palavras, frases, rimas e sons, analisando sua eficácia por meio da comparação dos desempenhos obtidos em testes de leitura realizados antes e após a utilização do programa.

Seguindo a metodologia proposta por Dehaene (2012), Castrillon (2013), os softwares educativos podem ser uma ferramenta de auxílio no ensino de crianças com dislexia. O primeiro passo é verificar quais são os

\footnotetext{
${ }^{4} \mathrm{O}$ software utilizado no projeto de extensão foi desenvolvido por uma das autoras do programa, por meio da pesquisa de doutorado. Hoje, os jogos têm auxiliado muitas crianças com dislexia.
} 
principais distúrbios apresentados no nível fonético pela criança. Isso pode ser feito a partir de propostas de leitura oral, para que se possa identificar o nível e as particularidades das dificuldades. Após reconhecer os principais processos desviantes durante o processo de leitura, o jogo no computador entra como uma ferramenta de intervenção para os problemas detectados.

O público-alvo desta pesquisa são crianças e jovens diagnosticados com dislexia. Para tanto, buscou-se a indicação junto à Secretaria de Educação do Município de Cerro Largo, para saber quais os alunos com diagnóstico, bem como os horários e locais do Atendimento Educacional Especializado (AEE) nas salas multifuncionais. Após a autorização pelo órgão de Educação (e aprovação deste projeto), buscou-se conhecer os alunos.

Assim que a pesquisadora obteve os nomes dos alunos (com dislexia), realizou um pré-teste, solicitando que eles fizessem a leitura de um texto narrativo para averiguar o grau de dificuldade de dislexia. Em seguida, iniciou com o processo de remediação por meio do uso do software.

O software foi desenvolvido pela coordenadora da pesquisa, em conjunto com profissionais da área da Ciência da Computação da empresa Affecty Systems, da cidade de Santo Ângelo/RS, e apresenta atividades e jogos educativos multimídias, próprios para crianças e jovens com dislexia. Para a elaboração das atividades, a pesquisadora baseou-se nas tecnologias assistivas e buscou, junto a Associação Brasileira de Dislexia, bem como no material Confias ${ }^{5}$ e nos embasamentos teóricos estudados nesta pesquisa, subsídios para elaborar as atividades. O software compreende um aplicativo que pode ser acessado em qualquer dispositivo com acesso à internet (computador, tablet, celular). As atividades buscam desenvolver estímulos para aumentar a consciência fonêmica a partir de jogos de identificação e reconhecimento de letras, palavras, rimas e sons. O aplicativo foi denominado Estimugame.

As crianças foram acompanhadas no período de um ano, uma vez por semana, no horário do Atendimento Educacional Especializado (AEE). Nesse período, desenvolveram as atividades com auxílio das pesquisadoras e bolsista. Após isso, as crianças foram submetidas, novamente, ao primeiro teste realizado, que se refere à leitura de textos narrativos, para verificar se houve melhoras ou não no processo de leitura, principalmente quanto às dificuldades arroladas no início da pesquisa.

\section{RESULTADOS E DISCUSSÕES}

\section{O aplicativo Estimugame}

Após a aplicação dos textos, a pesquisadora fez a leitura e a análise dos dados e, em torno das dificuldades apresentadas, desenvolveu, em conjunto com profissionais da área da Ciência da Computação da empresa

\footnotetext{
${ }^{5} \mathrm{O}$ Confias é um instrumento que tem como objetivo avaliar a consciência fonológica de forma abrangente e sequencial. Foi organizado por um grupo constituído por psicopedagogas, fonoaudiólogas, linguistas e psicóloga, na busca de um teste fidedigno para a avaliação da consciência fonológica em crianças brasileiras (MOOJEN, et al. 2014, p.10).
} 
Affecty Systems, da cidade de Santo Ângelo/RS, atividades e jogos educativos multimídias, próprios para crianças e jovens com dislexia, exibidos em forma de software com o objetivo de aplicar a segunda etapa dos testes nos participantes. Para a elaboração das atividades, a pesquisadora baseou-se nas tecnologias assistivas e buscou, junto à Associação Brasileira de Dislexia ${ }^{6}$, bem como nos embasamentos teóricos estudados nesta pesquisa, subsídios para elaborar cada tarefa proposta.

As atividades buscam desenvolver estímulos para aumentar a consciência fonêmica a partir de jogos de identificação e reconhecimento de letras, palavras, rimas e sons. Ao acessar o endereço eletrônico http://affecty.com/ estimugame (utilizando o navegador do Google Chrome, por indicação da empresa que auxiliou no desenvolvimento do programa), o participante deve inserir o nome de usuário e a senha, previamente cadastrados em conjunto com o administrador, conforme se observa na Figura 1.

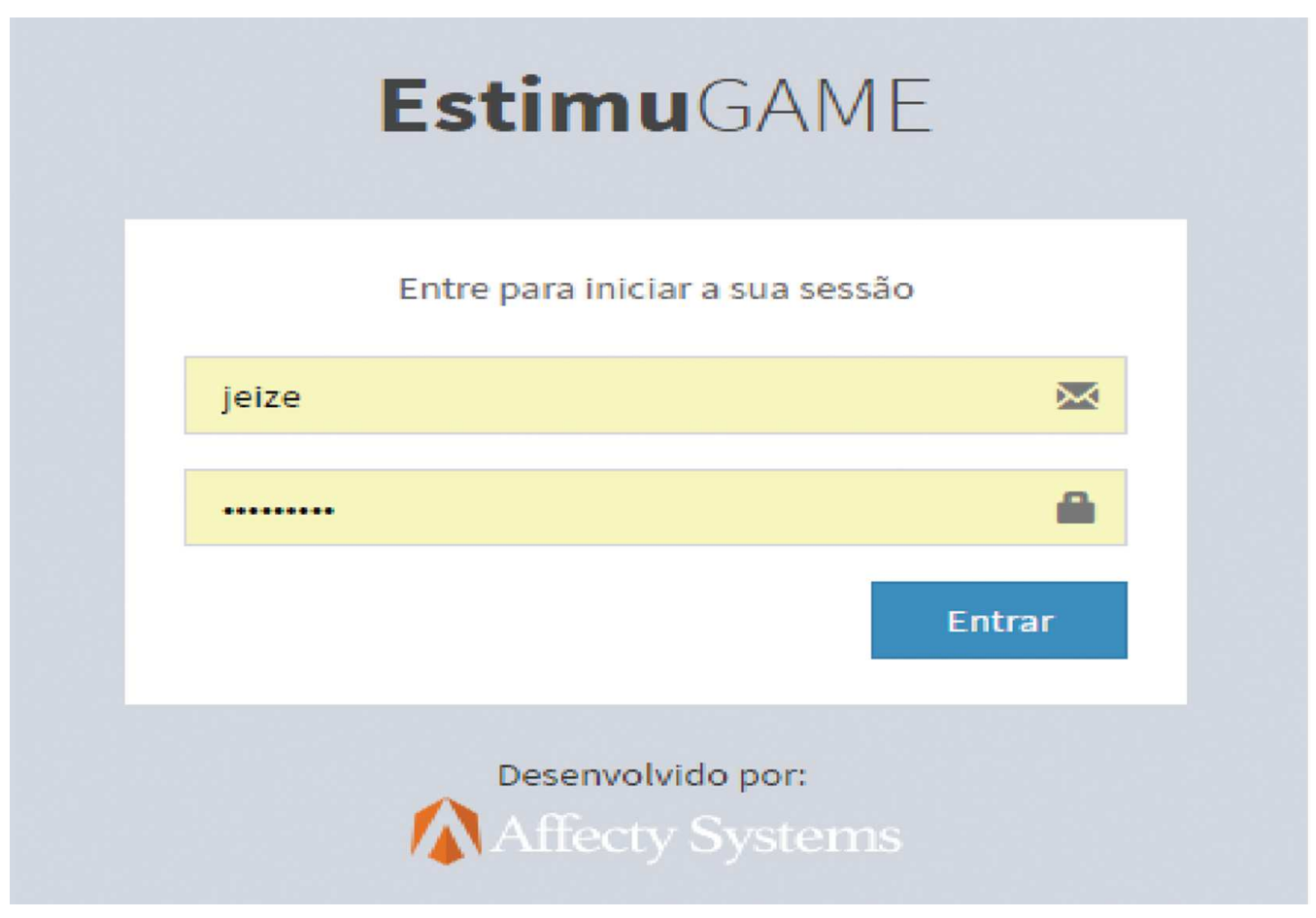

Figura 1 - Aplicativo foi denominado Estimugame.

Autoria: AUTORAS com assessoria da empresa Affecty Systems.

A partir disso, os usuários têm acesso ao menu principal, no qual podem selecionar, no menu de atividades, qual tarefa desejam desenvolver. Os jogos envolvem: repetir palavras/frases com multimídia, encontrar pares de letras, identificar letras, encontrar palavras diferentes, encontrar palavras camufladas e encontrar palavras que rimam. Após cada jogada, as respostas vão, aleatoriamente, mudando de lugar para que os participantes não as encontrem sempre na mesma disposição.

${ }^{6}$ Para maiores informações, segue endereço eletrônico da Associação Brasileira de Dislexia: https://www.dislexia.org.br/ 


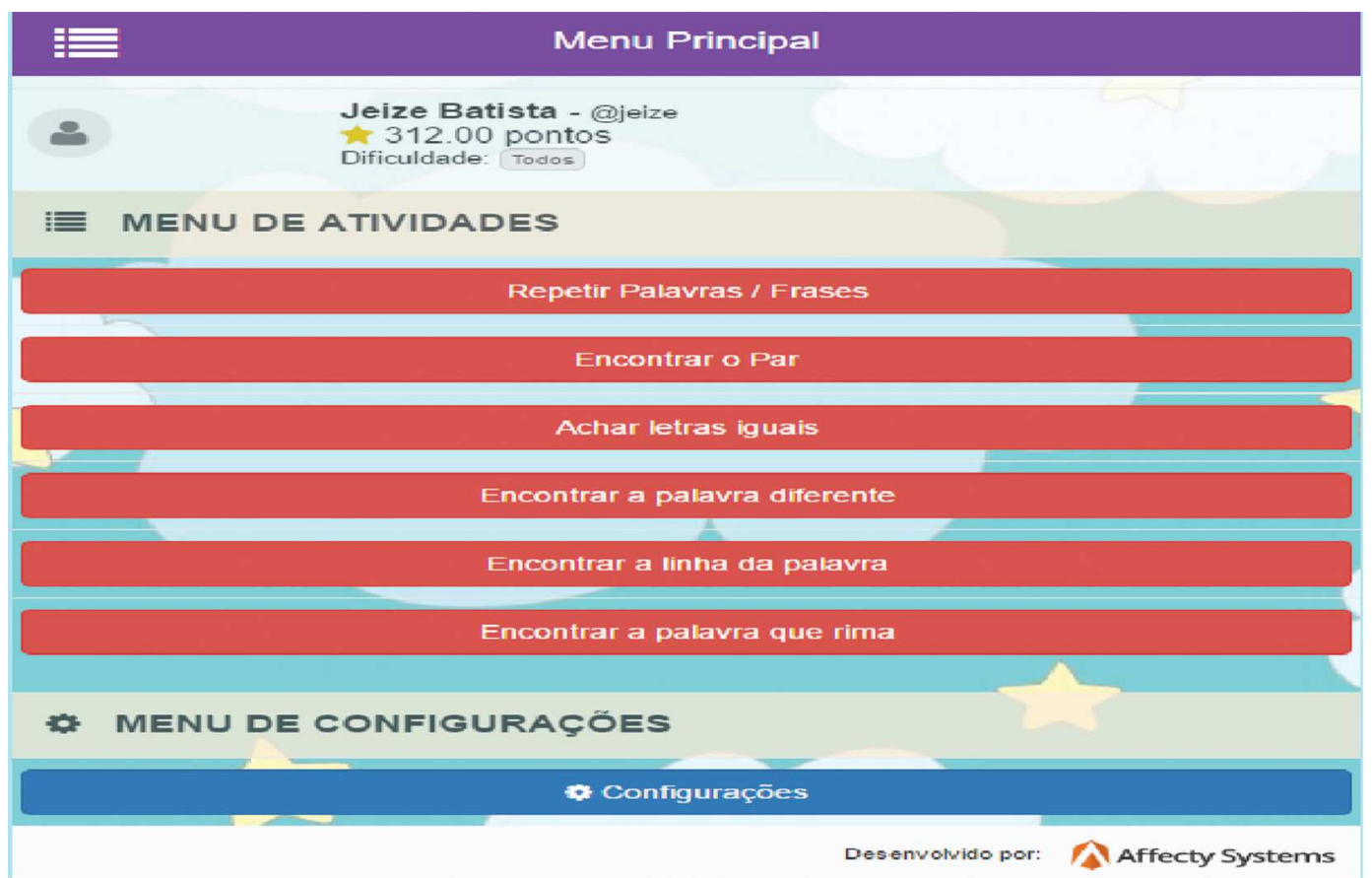

Figura 2 - Menu principal

Autoria: AUTORAS com assessoria da empresa Affecty Systems.

Também, no menu principal, o usuário encontra o menu de configurações, no qual pode selecionar o nível de dificuldade que pretende jogar: fácil, médio, difícil ou, se preferir, todos os níveis. Cabe destacar que a pontuação para cada acerto é proporcional ao nível de dificuldade de cada tarefa: 2 pontos para as fáceis, 4 pontos para as moderadas e 6 pontos para as difíceis.

A leitura do disléxico se dá de maneira silábica, devido a déficits básicos na codificação fonológica ou falta de organização segmental no nível das palavras bem como devido a distúrbios relativos à consciência fonológica. Assim, o disléxico soletra as letras e sílabas com dificuldade, buscando associar os sinais gráficos a um som da língua para chegar à palavra. Cabe lembrar, também, que há uma tendência a troca de letras, inversões silábicas, omissões, etc.

Dessa forma, as atividades propostas no software foram elaboradas com o propósito de desenvolver a consciência fonológica no nível das letras, sílabas, palavras e frases. Vale destacar que as atividades foram pensadas a partir da observação e descrição dos distúrbios apresentados pelos participantes durante a leitura oral dos textos utilizados como instrumentos neste estudo. Assim, a escolha das letras, sílabas, palavras e frases não foi aleatória, mas relacionada aos textos trabalhados. Cabe, porém, destacar que as atividades propostas no software podem ser modificadas pela pesquisadora, excluindo ou inserindo novas tarefas que envolvam outras necessidades relativas à dislexia e ao público alvo.

A primeira atividade proposta é a da repetição de palavras/frases, com recurso de multimídia (incluindo suportes de imagem, áudio e gravação). Como dito anteriormente, as palavras e frases foram reproduzidas partindo das dificuldades demonstradas pelos participantes na leitura oral dos textos narrativos. 
Todas as atividades são apresentadas aos usuários via áudio. A primeira tarefa está no nível da palavra e de frases, na qual os participantes ouvem os termos e devem repeti-los corretamente. Conforme instrução do Confias (MOOJEN, et al. 2014), foram usadas imagens correspondentes às palavras como instrumento lúdico para auxiliar na memória.

Nessa atividade, o participante visualiza a escrita da palavra, ouve a pronúncia e a repete. O mesmo procedimento ocorre também com as frases. Espera-se que por meio dessa tarefa os participantes estimulem progressivamente a habilidade da consciência dos fonemas e de sua correspondência com os grafemas, pronúncia e compreensão de palavras e frases.

Um exemplo: ao clicar no ícone que representa o som, o usuário ouve a seguinte sequência: "repita: paisagem" (ou qualquer outra palavra que estiver evidenciada). Assim, ele deve clicar no outro ícone que representa o microfone (em alguns aparelhos, permitir o uso do microfone se solicitado) e pronunciar a palavra corretamente. O mesmo ocorre com as frases. Se acertar, soma pontos e passa para a outra palavra/frase. Se errar, pode repetir a tarefa até acertar, ou seguir para próxima.

Na parte superior há o total de pontos que podem ser atingidos para cada atividade, o escore que o participante obteve e o nível da tarefa, conforme figura 3.

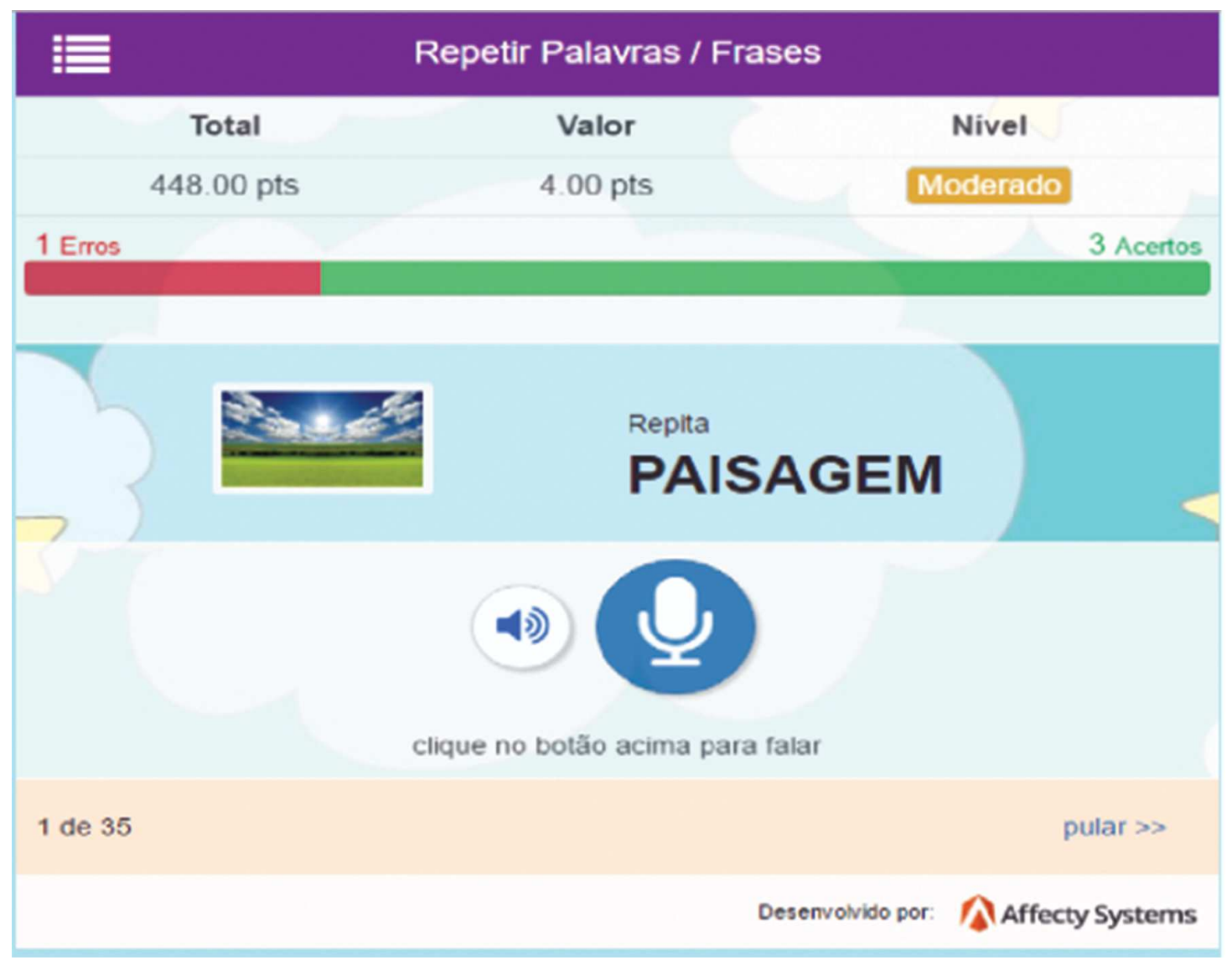

Figura 3 - Atividade de repetição de palavras e frases Autoria: AUTORAS com assessoria da empresa Affecty Systems. 
E, dessa forma, segundo os exemplos, a segunda proposta consiste em auxiliar o participante a encontrar sequências de letras iguais. Conforme observado, os participantes demonstraram, a partir do teste I (leitura dos textos narrativos), dificuldades em reconhecer a diferença gráfica e fonêmica entre algumas letras como "d","'b"e "p". Portanto, esta atividade busca uma reeducação cerebral pela prática da repetição e reconhecimento por meio do desenvolvimento das habilidades de ver/ler, ouvir, observar e executar a tarefa.

Nesta tarefa, ao clicar no ícone de som, o usuário ouve a seguinte ordem: "encontre a sequência igual a: adr" (o termo vem realçado em letras maiores e negritado. Abaixo haverá várias alternativas, que corresponderão ao nível de dificuldade, quanto mais difícil, mais alternativas para serem marcadas. Como em todas as tarefas, se acertar, o participante pontua e passa adiante e se errar, pode tentar novamente ou também passar para próxima atividade.

Como terceira tarefa, o usuário é incitado a encontrar as letras iguais. Assim como a atividade anterior, esta tarefa exige reconhecimento fonêmico e gráfico, na qual o participante terá que encontrar, entre as opções, todas as letras iguais (marcando mais que uma opção). Nesta atividade, o número de opções dependerá do nível de dificuldade da tarefa: fácil, moderada ou difícil. Quanto mais difícil, mais opções para marcar.

Assim, ao pressionar o ícone de som, o participante ouve a sentença: “encontre as letras iguais:” e abaixo aparece a letra "e". Como o nível de dificuldade dessa tarefa é moderado, são nove opções, na qual três deverão ser marcadas. Já as tarefas de nível fácil terão seis opções para duas corretas e as de nível difícil terão doze opções para quatro corretas. Destaca-se, ainda, que as opções corretas são alternadas de lugar a cada jogada.

A quarta atividade corresponde a encontrar a palavra diferente. As crianças e jovens disléxicos invertem as palavras de maneira total ou parcial, por exemplo, "casa" é lida "saca". Há, desse modo, uma troca na sequência de grafemas, pois o processamento da informação lexical entre os disléxicos, que é de ordem cerebral, está invertido ou simplesmente deficiente (ALMEIDA, 2008).

Logo ao acessar a atividade, o usuário ouve a proposta: "encontre a palavra diferente de"; logo abaixo, aparece o termo destacado e as alternativas dentre as quais deve achar a palavra diferente. Assim como na terceira atividade, o número de alternativas depende do nível de dificuldade da tarefa, entretanto somente uma alternativa estará correta em qualquer um dos casos, aparecendo sempre em lugares aleatórios a cada troca de jogada.

Nessa atividade, houve o cuidado para que o número de sílabas entre as palavras fosse igual e, mesmo com a troca silábica formando nome de pessoas, mantiveram-se letras minúsculas para não haver qualquer tipo de facilitador. Exemplo: caju “ “juca ou vida ““davi.

A quinta proposta convida o usuário a encontrar a palavra em meio a várias letras. É uma tarefa que demanda bastante atenção, na qual, entre várias letras diferentes, esconde-se uma palavra. Esta atividade busca desenvolver no disléxico a habilidade de percepção e reconhecimento grafo-fonêmico. 
Ao entrar nessa atividade, o usuário ouve a seguinte proposição: “em qual linha está a palavra........”, que é apresentada logo abaixo, em letras destacadas. Dependendo do nível de dificuldade da tarefa, será o número de linhas propostas: duas linhas para as consideradas fáceis, três linhas para as moderadas e quatro linhas para as difíceis.

$\mathrm{Na}$ sexta tarefa, o participante deverá encontrar a palavra que rima. O trabalho com rimas serve para estimular a consciência fonológica, ou seja, a capacidade de perceber a estrutura sonora da palavra. É importante para o disléxico perceber que peteca rima com sapeca, por exemplo. Dessa forma, ele vai assimilando e correlacionando os sons e as palavras. Em outra etapa da leitura, todos esses elementos serão associados ao significado das palavras facilitando a compreensão e leitura dos textos.

Ao iniciar essa atividade, o usuário ouvirá a seguinte sentença: "encontre a palavra que melhor rima com ." e logo abaixo, em letras maiúsculas de tamanho maior, negritada a palavra na qual deverá partir para encontrar a rima. Algumas alternativas propostas apresentam uma manipulação semântica, como no exemplo: para tubarão, as alternativas são: peixe, balão, mar. Peixe e mar não rimam com tubarão, entretanto há uma associação de significados que os envolve. O objetivo é reforçar a relação do usuário com as palavras a partir da associação gráfico-fonêmica e semântica.

Em outras alternativas, pensou-se em trabalhar com o jogo entre as sílabas: sacola rima com - escola, casaco e saco. As opções apresentadas mantêm sílabas que compõem a estrutura da palavra principal. Como ocorre de o disléxico trocar sílabas e inverter palavras, essa tarefa busca estimular a memória visual.

O aplicativo também permite ao administrador acompanhar os usuários quanto aos erros e acertos obtidos nas tarefas, bem como ao número de acessos e tempo destinado às atividades por meio de um relatório de cada usuário. Além disso, possibilita ao administrador inserir novos usuários e acrescentar, modificar ou excluir atividades no aplicativo de acordo com as necessidades sentidas.

Percebe-se, então, que a elaboração do software atende ao proposto no estudo e serve como ferramenta de auxílio por meio de atividades que possam favorecer e estimular alunos com dificuldades de leitura, diagnosticados com dislexia. É um aplicativo que propõe estratégias de reeducação sob forma de atividades similares a jogos no computador, com níveis de dificuldade, registro sistemático do progresso, facilidade de acesso, em casa ou na escola. E, retomando Castrillon (2013), não são apenas joguinhos, mas atividades que oferecem desafios gradativos, de acordo com a taxa de sucesso do aluno e, além disso, produzem feedback para o educador, na medida em que computam os erros e acertos dos participantes possibilitando acompanhar a progressão dos usuários de forma individual.

O software foi produzido a fim de auxiliar as crianças ativando os mecanismos neuronais, assim, auxiliando no desenvolvimento da consciência fonêmica e consequentemente na compreensão da leitura. Desse modo, a partir do projeto de extensão, tem-se possibilitado que muitos alunos com dislexia recebam um auxílio específico para as dificuldades de leitura, o que vem se mostrando eficaz a cada semana. Todos os participantes estão acompanhando e superando, mesmo que lentamente, suas limitações, buscando melhorar a cada etapa do projeto. 


\section{$O$ uso dos jogos computacionais (softwares) como ferramentas de ensino-aprendiza- gem no desenvolvimento da leitura de alunos com dislexia}

As TICs são, hoje, uma questão de possibilidades e novos caminhos para a educação. Com o desenvolvimento dos recursos tecnológicos, juntamente com a tendência do mundo de tornar-se cada vez mais informatizado, torna-se inevitável ressaltar a importância da informática aplicada ao ensino. Ainda, cabe considerar que as TICs podem ser utilizadas por meio das Tecnologias Assistivas (TA):

Tecnologia Assistiva (TA) é um termo utilizado para identificar todo o arsenal de recursos e serviços que contribuem para proporcionar ou ampliar habilidades funcionais de pessoas com deficiência e consequentemente promover vida independente e inclusão (BERSCH \& TONOLLI, 2006, p. 02).

Desse modo, as TAs podem ser consideradas como um recurso de intervenção que serve à pessoa com deficiência, promovendo maior eficiência e autonomia. Conforme Radabaugh (1993), a tecnologia torna as coisas mais fáceis para as pessoas sem deficiência. Entretanto, para as pessoas com deficiência, a tecnologia torna as coisas possíveis.

Assim, a TA deve ser entendida como um auxílio que promoverá a ampliação de uma habilidade funcional deficitária ou possibilitará a realização da função desejada e que se encontra impedida por circunstância de deficiência. Dessa forma, é possível afirmar que o objetivo maior da TAé proporcionar à pessoa com deficiência maior independência, qualidade de vida e inclusão social, através da ampliação de suas habilidades de aprendizado (BERSCH \& TONOLLI, 2006).

O conceito de inclusão defende a ideia de que todas as crianças podem aprender e fazer parte de uma vida escolar e comunitária para que haja oportunidades de construção de conhecimentos. Ocorre que, no momento em que essas crianças com dificuldades de aprendizagem ingressam em um sistema escolar tradicional, frequentemente vivenciam situações de frustrações e desapontamentos, o que torna urgente a busca de caminhos que promovam autonomia e favoreçam a integração.

Um exemplo de alternativa são os softwares que propõem atividades e jogos online, com reconhecimento de voz, grafemas e fonemas, promovendo o desenvolvimento da consciência fonológica em alunos com dislexia, reconhecendo suas limitações e ampliando seu universo de aprendizagem (DEHAENE, 2012).

Nesse mesmo sentido, Neto e Herculani (2011) destacam que softwares são criados a todo o momento, com objetivos diversos; porém, quando se busca implementar um sistema para facilitar o aprendizado de pessoas com dificuldades de aprendizagem, é imprescindível analisar quais são os requisitos necessários para a utilização do mesmo, para que o usuário final consiga usufruir de todos os seus recursos, tornando o software uma ferramenta de ensino. Os autores ressaltam, ainda, que cada deficiência possui um grau de variação. Assim, torna-se necessário desenvolver aplicações para cada necessidade especial, sendo que o software deve ser programado para suprir algumas deficiências, não todas. Assim, é possível desenvolver as habilidades comprometidas pela deficiência (NETO E HERCULANI, 2011). 
Desse modo, é necessário que o professor, além da sua área específica, também busque conhecimentos em tecnologia, para que possa manusear, produzir e disponibilizar as ferramentas aos seus alunos. Da mesma forma, os alunos precisam aprender a utilizar os instrumentos, a fim de que possam realizar as tarefas autonomamente (MACHADO \& SANTOS, 2013).

Sob esse aspecto, não basta somente ter computadores ou meios digitais se os professores não forem capazes de uma relação educativa coerente entre seu trabalho e as ferramentas. Ou seja, o professor é quem dá o sentido pedagógico ao processo. Se ensinar dependesse só de tecnologias, já teríamos achado as melhores soluções há muito tempo. Elas são importantes, mas não resolvem as questões de fundo (MORGAN, 2009).

Nesse mesmo sentido, Leffa (2006) destaca que o computador não substitui o livro ou o professor e ressalta que ele é apenas um instrumento, mas necessário. Dessa forma, o professor tem um papel de estimulador do aprendizado do aluno, despertando nele a curiosidade em conhecer, em pesquisar, e buscar a informação mais relevante, contemplando o uso das TICS que melhor se adaptem ao seu método de ensino.

O mundo está avançando cada vez mais, e a educação precisa acompanhar esse caminho. Não se pode somente pensar em uma aula aos moldes tradicionais de ensino, principalmente quando pensamos nos alunos com dificuldades de aprendizagem.

Dessa maneira, torna-se indiscutível o uso das TIC na sala de aula. Contudo, ainda é necessário pensar em como elas podem auxiliar no processo de ensino-aprendizagem dos alunos de maneira a promover o conhecimento. Para isso, cabe aos protagonistas da história determinar o sucesso dessa aplicação, como instituições de ensino, os professores e os alunos.

\section{O software: uma metodologia de intervenção}

As pesquisas relacionadas à dislexia sugerem que as dificuldades de leitura na maioria das crianças são causadas por déficits básicos na codificação fonológica ou falta de organização segmental no nível das palavras e frases. Em diversos estudos apresentados por pesquisadores da área, percebe-se que não há cura para dislexia, entretanto, é possível buscar caminhos que amenizem os sintomas com metodologias e tratamentos que diferenciam a forma de aprendizado.

De acordo com Castrillon (2013), é importante atentar para o fato de que ninguém aprende a ler sem fazer parte de uma comunidade de aprendizagem sobre um cérebro em desenvolvimento. $\mathrm{O}$ autor ainda ressalta que, sem participar de uma comunidade de aprendizagem, onde o letramento é prática significativa, fica muito difícil aprender a ler, principalmente por não haver uma mediação educadora, sejam crianças disléxicas, ou não. Assim, cabe aos educadores e aos especialistas desenvolver respostas instrucionais flexíveis e caminhos que favoreçam o sucesso escolar possível para cada aprendiz, independente do nível de dificuldade. 
Programas remediativos devem ser utilizados de forma intensiva e sistemática, para que novas aprendizagens e competências executivas sejam fixadas e generalizadas. Estes programas, disponíveis comercialmente ou em publicações científicas, têm como objetivo promover o desenvolvimento de competências específicas em duas grandes áreas: codificação/ decodificação (mecânica) e compreensão (semântica). O aluno disléxico deve ter acesso a esta instrução suplementar fora da sala de aula, com o educador especializado, que irá escolher os melhores instrumentos e orientar na execução das atividades (CASTRILLON, 2013, p, 397).

Uma alternativa proposta por Dehaene (2012) é a reeducação sob forma de jogo no computador. Ressalta que os jogos mais competitivos detectam o nível da criança e automaticamente se adaptam acompanhando o progresso das crianças.

Nesse mesmo sentido, Castrillon (2013) salienta que os programas computadorizados apresentam oportunidades diferenciadas para a sua prática, bem como ajuste com o grau de dificuldade de acordo com o nível instrucional de cada aprendiz; interface motivadora; registro sistemático do progresso; facilidade de acesso, em casa ou na escola. Também enfatiza que softwares de remediação não são apenas joguinhos, mas atividades que oferecem desafios gradativos, de acordo com a taxa de sucesso do aluno e, além disso, produzem feedback para o educador.

Segundo Sampaio (2014), os jogos ou programas mais eficazes para desenvolver as habilidades de leitura, como em crianças com dislexia, são aqueles que procuram reforçar as habilidades das crianças em consciência fonológica, nomes de letras e sons, leitura e ortografia de palavras e leitura de frases simples. A autora ainda sugere um programa de reeducação que inclua: atividades que desenvolvam a consciência fonológica - perceber, identificar e manipular os sons da linguagem oral; reconhecimento fônico-como as letras e os grupos de letras representam os sons da linguagem oral; um trabalho com pronúncia - decodificação e, ainda, leitura de palavras à primeira vista (SAMPAIO, 2014).

Dehaene (2012) destaca que há mais de vinte anos, uma série de especialistas da área da leitura vem desenvolvendo estratégias de reeducação. O objetivo da maior parte delas é expandir a consciência fonêmica por meio de manipulações de letras e de sons.

É possível, portanto, perceber que as atividades no computador podem tornar-se ferramentas que contribuam para o desenvolvimento da aprendizagem da criança disléxica. Logicamente que essas atividades devem ser dosadas em sessões cotidianas e renovadas ao longo das semanas. Muitos estudos e pesquisas demonstram que a plasticidade cerebral no homem é maximizada pela repetição intensa de uma mesma tarefa, intercalada por períodos de descanso. Entretanto, é importante que a reeducação suscite na criança atenção e prazer (DEHAENE, 2012).

Dessa forma, ao se tentar entender e ajudar os alunos, pesquisadores e professores estarão melhorando o ensino para todos na sala de aula. Estratégias e novas metodologias de intervenção podem e devem ser desenvolvidas para remediar dificuldades específicas.

O certo é que existem maneiras de superar os problemas e amenizar as dificuldades apresentadas, avançando na compreensão das bases neurais da leitura em crianças disléxicas, auxiliando-as de forma efetiva no 
processo de aprendizagem, promovendo um espaço para que ela possa "sentir" as letras, reconhecendo grafemas, morfemas e sons, estimulando as habilidades fonológicas e consequentemente de compreensão, minimizando o impacto da dislexia em suas vidas.

Sendo assim, com base nos pressupostos teóricos estudados até aqui, este trabalho buscou aplicar, em alunos diagnosticados com dislexia, da rede municipal de ensino de Cerro Largo/RS, um software com jogos que promovam a reeducação da leitura por meio do desenvolvimento da consciência fonológica. À vista disso, no próximo ponto, será abordado sobre o uso dos jogos como atividade de intervenção às dificuldades de aprendizagem.

\section{Revisão sobre o uso dos jogos como intervenção às dificuldades de aprendizagem}

Alunos com dificuldades de aprendizagem em decorrência da dislexia estão cada vez mais presentes nas salas de aula. $O$ fato é que essa realidade tem sido um desafio para os profissionais de educação que buscam alternativas e métodos para ajudar os alunos no desenvolvimento de suas competências.

De acordo com Castrillon (2013), contrapondo-se à ideia de que o aluno não aprende porque não quer, alguns educadores perceberam que a fonte do fracasso estaria nos defeitos estruturais da instituição escolar, causados pelo conservadorismo ou até mesmo pelo despreparo humano e material de algumas instituições.

Ocorre que, independentemente de culpados, a realidade educacional e as dificuldades de aprendizagem precisam ser pensadas e consideradas no planejamento educativo. Segundo Castrillon (2013), as estratégias de intervenção desenvolvidas para remediar dificuldades específicas têm provado seu valor pedagógico para a população estudantil em geral em vários países, como Portugal, Estados Unidos, Panamá e França, em forma de softwares com jogos educativos. No Brasil, como relatado no item anterior, essa é uma prática ainda pouco desenvolvida que tem despertado mais interesse entre profissionais da área médica.

As descobertas relacionadas à plasticidade cortical para quem tem dislexia conduziram à criação de um programa de intervenção baseado em treinos sucessivos, denominado "Fast ForWord" (MERZENICH et.al. 1996; TALLAI et al., 1996). A hipótese é a de que este treinamento levaria a uma reorganização neuronal e, assim, a uma melhora no desenvolvimento das habilidades de linguagem. Os treinos seriam realizados por meio de um programa computadorizado, no qual palavras, sentenças e estímulos não verbais (imagens) seriam expandidos.

O treinamento, voltado para crianças de 5 a 10 anos de idade, continha dois jogos audiovisuais, sendo um verbal e outro não verbal. No jogo não-verbal, a criança ouvia um par de estímulos auditivos, apresentando características semelhantes aos fonemas do inglês, e deveria associá-los aos estímulos visuais correspondentes na tela, na ordem correta (exemplo: sons com animais correspondentes). No jogo verbal, a criança ouvia um par de sílabas compostas por consoante e vogal, e deveria associá-las aos símbolos da tela, na ordem correta (somgrafo-fonêmico). Os jogos eram adaptados automaticamente de acordo com o desempenho da criança. Para 
treinar a efetividade dos jogos, sete crianças com alterações de linguagem foram submetidas aos jogos, durante quatro semanas, por 20 minutos por dia. Os resultados mostraram que, das sete crianças treinadas, cinco apresentaram evolução no desempenho, dia após dia (MERZENICH et al. 1996).

De acordo com Thibodeau (2007), três pontos devem ser considerados em um treinamento computadorizado: o tipo de estímulo (com utilização de imagens, recursos multimídias, jogos desafiadores), o fato da interação ser ativa por parte do participante e a frequência com que o treino é realizado. Para Kelly e Garavan (2005), a prática decorrente de tarefas com jogos computacionais em crianças com dislexia pode resultar em mudanças na ativação cerebral como o aumento da ativação em áreas cerebrais envolvidas com a tarefa ou a reorganização da atividade cerebral. Musiek (2002) destaca duas formas de reorganização. A primeira envolvendo a ativação de neurônios ou conexões neurais previamente inativas, e a segunda envolvendo o surgimento de novas conexões.

Baseados no treinamento de intervenção a partir de jogos computacionais para crianças com dislexia, pesquisadores franceses desenvolveram um software e o aplicaram em um grupo de 12 crianças diagnosticadas com dislexia entre 7 e 12 anos de idade. Essas crianças receberam o treinamento durante cinco semanas, sendo cinco vezes por semana, durante uma hora diária. As atividades continham exercícios de processamento fonológico, testes de leitura, atenção e reconhecimento grafo-fonêmico. Os resultados mostraram que o grupo em estudo apresentou melhora significante no desempenho da consciência fonológica (MERZENICH et al. 1993).

Num segundo estudo, o mesmo treinamento foi aplicado em 29 crianças com dislexia, entre 5 e 12 anos de idade, durante seis semanas, sete vezes por semana e 15 minutos por dia. Parte do treinamento era feito na escola e outra parte na casa de cada participante, com acompanhamento dos pais.

Foram realizadas modificações nas tarefas propostas nos jogos para que o nível de dificuldade fosse compatível à idade dos participantes, já que nessa intervenção havia crianças menores. Os resultados mostraram que o treinamento foi eficiente para maioria das crianças (72\%), inclusive para as crianças de cinco anos de idade (MERZENICH et al. 1993).

Castrillon (2013) ressalta que o trabalho de intervenção deve focar em dificuldades específicas. O educador responsável pode acompanhar e observar o desempenho de cada aprendiz e como ele responde aos desafios instrucionais. $\mathrm{O}$ trabalho com jogos educativos para crianças com dificuldades de aprendizagem deve partir de diagnóstico, levantamento de dados, para daí se pensar nas atividades de intervenção, bem como tempo de jogo e nível das tarefas.

A autora ainda salienta que as atividades podem ser individuais ou em pequenos grupos (de 5 alunos no máximo), de acordo com a natureza e o grau dos déficits identificados por meio de diagnóstico e sondagens. Acrescenta que os jogos para os disléxicos devem estimular a prática de competências básicas, baseadas na repetição, reconhecimento de sons, rimas, palavras, frases e sílabas (CASTRILLON, 2013). 
Para Dehaene (2012), os softwares educativos podem ser uma ferramenta de auxílio no ensino de crianças com dislexia. O primeiro passo é verificar quais são os principais distúrbios apresentados no nível fonético pela criança. Isso pode ser feito a partir de propostas de leitura oral, para que se possa identificar o nível e as particularidades das dificuldades. Após reconhecer os principais processos desviantes durante o processo de leitura, o jogo no computador entra como um tratamento de intervenção para os problemas detectados.

A partir do exposto, é possível perceber que os jogos computacionais foram eficazes para maior parte das crianças testadas. Os softwares tem sido uma prática desenvolvida fora do Brasil e têm demonstrado resultados positivos em relação à melhoria do desempenho fonológico em crianças com dislexia.

Diante disso, acredita-se no uso dos jogos como intervenção às dificuldades de aprendizagem, principalmente no que se refere a crianças com dislexia, foco principal deste estudo. É necessário, diante da realidade que se tem nas salas de aula, que o Brasil também desenvolva pesquisas na área de Letras com treinamentos que possam mostrar resultados e auxiliar no processo de ensino e aprendizagem dos alunos.

\section{CONCLUSÕES}

Este trabalho foi elaborado com o objetivo de apresentar o desenvolvimento de um projeto de extensão proposto para auxiliar as salas de recurso das escolas do município de Cerro Largo, a partir do uso de um software como tratamento remediativo para alunos diagnosticados com dislexia. As atividades promovem estímulos para ampliar a consciência fonêmica a partir de jogos de identificação e reconhecimento de letras, palavras, frases, rimas e sons, aplicando e analisando sua eficácia por meio da comparação dos desempenhos obtidos em testes de leitura realizados antes e após a utilização do programa.

Até o momento, todos os participantes têm demonstrado progressos em relação à leitura. Os alunos têm sido assíduos e participam ativamente das atividades propostas pela bolsista de Letras. Ao todo são quinze participantes e os níveis de dislexia variam entre intermediário e avançado. Todos estão motivados e, com isso, espera-se alcançar resultados positivos até o final do processo.

Desse modo, espera-se que até o fim do desenvolvimento deste projeto, muitos problemas ainda sejam superados pelos participantes, que o software seja um exemplo de alternativa metodológica, abrindo caminhos para novas propostas escolares que atendam às diferentes necessidades dos alunos, promovendo, assim, uma educação inclusiva e igualitária para todos.

O certo é que o uso das tecnologias nas escolas vem se ampliando cada vez mais nesse novo cenário do século XXI. No entanto, é necessário que esse avanço seja utilizado adequadamente e, principalmente, que os educadores estejam capacitados a desenvolver projetos agregadores a partir do uso tecnológico, potencializando o trabalho com tarefas didáticas, promovendo atividades que atendam às necessidades específicas de aprendizagem, contribuindo para tornar mais significativo o processo de aprender. 
Diante disso, espera-se que este trabalho possa contribuir para auxiliar os profissionais de ensino diante das dificuldades dos alunos com dislexia, respeitando suas limitações e reconhecendo-os como seres humanos capazes que, mesmo com problemas de aprendizagem, podem vencer os obstáculos e construir seus conhecimentos. A dislexia não tem cura, mas pode ser amenizada com metodologias e estratégias que desenvolvam as habilidades e contribuam como estratégia de intervenção para os processos desviantes apresentados pelos alunos durante a leitura.

\section{REFERÊNCIAS BIBLIOGRÁFICAS}

ABD - ASSOCIAÇÃO BRASILEIRADE DISLEXIA. Disponível em: <http://dislexia.org.br/v1/index.php/ health-living-c/140-como-interagir-com odislexico-em-sala-de-aula>. Acesso em: 11 Abr. 2016.

ALMEIDA, Marina da Silveira Rodrigues. Dislexia. Planeta Educação, 2008. Disponível em:<http:// www.planetaeducacao.com.br/portal/artigo.asp?artigo=1328>. Acesso em: 15 Abr. 2016.

BERSCH Rita. TONOLLI, José. Tecnologia Assistiva. 2006. Disponível em: < http://www. assistiva. com.br/>. Acesso em: 13 Abr. 2016.

CASTRILLON, Luciana Maria Teixeira. Problemas de aprendizagem, soluções de aprendizagem: respostas instrucionais para as necessidades de cada aprendiz. In: ALVES, Luciana; MOUSINHO, Renata; CAPELLINI, Simone. Org(s). Dislexia: novos temas, novas perspectivas. Rio de Janeiro: Wak Editora, 2013. p. 371-404.

DEHAENE, Stanislas. Os neurônios da leitura: como a ciência explica nossa capacidade de ler. Porto Alegre: Penso, 2012.

KELLY \& GARAVAN H. Human functional neuroimaging of brain changes associated with practice. Cereb Cortex, 2005.

LEFFA, Vilson J. A aprendizagem de línguas mediada por computador. In: Vilson J. Leffa. (Org.). Pesquisa em linguística Aplicada: temas e métodos. 1ed. Pelotas: Educat, 2006, v. 1, p. 11-36.

MACHADO, Vanessa. \& SANTOS, Cristina Paludo. Requisitos de Interação em Softwares Inclusivos para Pessoas com Deficiência Intelectual.TCC: Ciências da Computação/ URI- Campus de Santo Ângelo, 2013.

MERZENICH, M. Temporal information processing in the nervous system: special reference to dyslexia and dysphasia. New York: New York Academy of Sciences, 1993.

MERZENICH, M.; TALLAI P. Temporal Processing Deficits of language-learning impaired children ameliorated by training. Science, 1996.

MOOJEN, Sônia (coord.); LAMPRECHT, Regina; SANTOS, Rosangela M.; FREITAS, Gabriela M.; BRODACZ, Raquel; SIQUEIRA, Maity; COSTA, Adriana C.; GUARDA, Elisabet. . CONFIAS:

Consciência Fonológica: instrumento de Avaliação Sequencial. São Paulo: 3 ed - Casa do Psicólogo, 2014. 
MORGAN, J. M.. A educação que desejamos: Novos desafios e como chegar lá. Artigo publicado em 2009. Disponível em: <http://periodicos.puc-campinas.edu.br/seer/index.php/reveducacao/article/viewFile/ 121/108> Acesso em: 13 Jun. 2016.

MUSIEK, F. Processing Dissorders. Seminars in Hearing, 2002.

NETO, Mário. HERCULANI, Cristóvam. Ferramenta para pessoas com necessidades especiais:

Giusticalc. São Paulo: REVISTAFATEC, artigo 4º V. 2, 2011.

RADABAUGH, M. P. NIDRR's Long Range Plan - Technology for Access and Function Research Section Two: NIDDR Research Agenda Chapter 5: TECHNOLOGY FOR ACCESS AND FUNCTION. 1993. Disponível em: <http://www.ncddr.org/rpp/techaf/lrp_ov.html> Acesso em: 08 Jun. 2016.

SAMPAIO, S. Aspectos Neuropsicopedagógicos da Dislexia e sua influência em sala de aula. In: SAMPAIO, S. FREITAS, I. B. (Orgs.) Transtornos e dificuldades de aprendizagem: entendendo melhor os alunos com necessidades educativas especiais. $2^{\mathrm{a}}$ Ed. Rio de Janeiro: Wak Editora, 2014.

THIBODEAU, LM. Computer-based Processing Disorders. Volume II: Comprehensive Intervention. San Diego: Plural Publishing, 2007.

UNESCO. Relatório da Reunião de Consultoria Especializada. TIC Acessíveis e Ensino Personalizado para Alunos com Deficiências: Um diálogo entre Educadores, Indústria, Governo e Sociedade Civil. Paris: Sede UNESCO, 2011.

Submetido em: 10/06/2020 Aceito em: 12/06/2020. 